\section{ON MIRAGE*}

THE name of "Mirage" is applied to certain illusory appearances due to excessive bending of the rays of light in their passage through the atmosphere. These appearances are by no means uniform.

Sometimes, especially in hot countries, the observer loses sight of the ground beyond a certain distance from his position, and sees in its stead, what looks like a sheet of water, either calm or with movements resembling waves; and if any distant objects are sufficiently lofty to be seen above this apparent lake, their images are seen beneath the objects themselves, inverted as if by reflection in this imaginary water. The dry and hot soil of Egypt is famous for the production of this form of the phenomenon. It is also mentioned as of frequent occurrence in the plains of Hungary, in the plain of $\mathrm{La}$ Crau in the South of France, and in the fen districts of England when dried up by the summer heat. It is also common in Australia. The Deputy Surveyor-General of South Australia once reported the existence of a large inland lake, which on further examination turned out to be nothing but a mirage.

Another class of appearances are known (especially among nautical men) under the name of looming. Distant objects are said to loom when they appear abnormally elevated above their true positions. This abnormal elevation not unfrequently brings into view objects which in ordinary circumstances are beyond the horizon. It is also frequently accompanied by an appearance of abnormal proximity (though this may perhaps be rather a subjective inference from the unusual elevation and clear visibility of the objects than a separate optical characteristic), and it is further accompanied in many, though not in all cases, by a vertical marnification, the heights of objects being many times magnified in comparison with their horizontal breadths, so as to produce an appearance resembling spires, pinnacles, columns, or basaltic cliffs. Some beautiful descriptions of these latter appearances, with illustrative plates, are given in Scoresby's "Greenland," the objects thus magnified being icebergs; and a very full and interesting account of the phenomena of mirage, as observed in high latitudes, will also be found in the "Arctic Regions" of the same author.

It is usually across water that looming is observed; and as a surface of water stands naturally in contrast with a sanily desert or a surface of parched land, so also the optical effects produced are, in a manner, opposite. The inverted images which are often presented in looming are not beneath the object, as in the case of mirage on dry land, but above it, as is formed by reflection in the sky. The only examples that $I$ have myself seen of mirage were of this kind. They were seen across sheets of calm water, the hills on the other side being seen with fictitious hills upside down resting on the tops of the real hills. In rare instances, two or $\epsilon$ ven three of these images are seen one above another, vertically over the real object; but these multiple images are usually too small to be seen without the aid of a telescope-the objects whose images they are being so distant as to appear mere specks to the naked eye.

There is always more or less of change observable in the images formed by mirage, and the changes are greatest and most sudden when the images are most distorted, as compared with the true forms of the objects. The appearances also change with the height of the observer's eye. Looming is seen to the greatest advantage from an elevated position, such as the mast-head of a ship. The mirage of dry land is sometimes visible at any moderate height, but in other cases-especially in countries which are not very hot-the range of height from which it is visible is extremely limited. A very fine mirage, recently observed in the fen districts, was only

* A Paper read by Prof. J. D. Everett, M.A., D.C.L., before the Belfast atural History and Philosophical Society. seen when the observer was on the top of the marsh wall. But this case seems to have been peculiar. It was accompanied by the further peculiarity that a strong wind was blowing-the general rule being that mirage is only seen in calm weather. Observers of mirage on the sands of Morecambe Bay, and of the Devonshire coast, state that it could frequently be only seen by stooping.

Mirage is seldom seen in winter. The hot shining of the sun seems to be an invariable antecedent; and this is true even of the polar regions, where Capt. Scoresby attributes the phenomenon to "the rapid craporation which takes place in a hot sun from the surface of the sea, and the unequal density occasioned by partial condensations, when the moist air becomes chilled by passing over considerable surfaces of ice."

Time will not allow me to do much in the way of quoting the very numerous records which exist. Scoresby's accounts alone would almost suffice to occupy the evening, and I would zgain refer to them as models of accurate observation and effective description. I will content myself with quoting nearly in full the account of a mirage observed at Hastings and neighbouring parts of the south coast of England in 1798 , as given in the Philosophical Transactions for that year, the narrator being Mr. Latham, F.R.S. :-

"On Wednesday last, July 26, about five o'clock in the afternoon, whilst I was sitting in my dining-room at this place (Hastings), which is situated ucon the parade, close to the sca-shore, nearly fronting the south, my attcntion was excited by a great number of people running down to the sea-side. Upon inquiring the reason, I was informed that the coast of France was plainly to be distinguished with the naked eye. I immediately went down to the shore, and was surpriscd to find that, even without the assistance of a telescope, I could very plainly see the cliffs on the opposite coast, which at the nearest part are between forty and fifty miles distant, and are not to be discerred from that low situation by the aid of the best glasses. They appeared to be only a few miles off, and seemed to extend for some leagues along the coast. I pursued my walk along the shore to the eastward, close to the water's edge, conversing with the sailors and fishermen on the subject. They at first could not be persuaded of the reality of the appearance, but they soon became so thoroughly convinced, by the cliffs gradually apperring more clevated and approaching nearer, as it were, that they pointed out and named to me the different places they had been accustomed to visit, such as the Bay, the Old Head or Man, the Windmill, \&c., at Boulogne, St. Valéry, and other places on the coast of Picardy, which they afterwards confirmed when they viewed them through their telescopes. Their observations were, that the places appeared as near as if they were sailing at a small distance into the harbours.

"Having indulged my curiosity upon the shore for near an hour, during which the cliffs appeared to be at some times more bright and near, at others more faint, and at a greater distance, but never out of sight, I went upon the eastern cliff, which is of a very considerable height, when a most beautiful scene presented itself to my view; for I could at once see Dungeness, Dover cliffs, and the French coast, all along from Calais, Boulogne, \&c., to St. Valéry, and, as some of the fishernen affirmed, as far to the westward as Dicppe. By the telescope, the French fishing-boats were plainly to be seen at anchor, and the different colours of the land upon the heights, together with the buildings, were perfectly discernible. This curious phenomenon continued in the highest splendour till past eight o'clock, . . . when it gradually vanished. The day was extremely hot, . . . not a breath of wind was stirring the whole of the day. . . A few days afterwards I was at Winchelsea, and at several places along the coast, where I was informed the above phenomenon had been easily visible. 
"I should also have observed that when I was upon the eastern hill, the cape of land called Dungeness, which extends nearly two miles into the sea, and is about sixteen miles distant from Hastings, in a right line, appeared as if quite close to it, as did the fishing-boats and other vessels which were sailing between the two places. They were likewise magnified to a great degree."

I have stated that the phenomena which constitute mirage are due to the bending of rays of light in the atmosphere, and I now proceed to point out the princip?es by which this bending is governed.

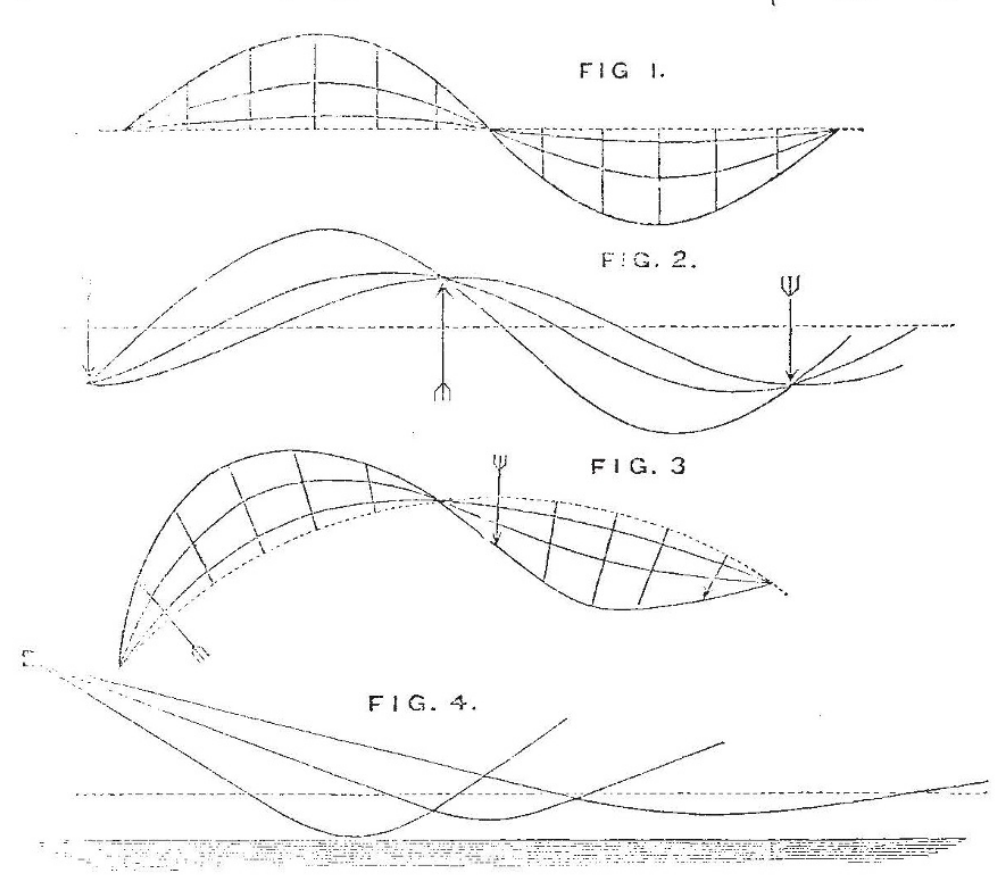

FIG. 5 .
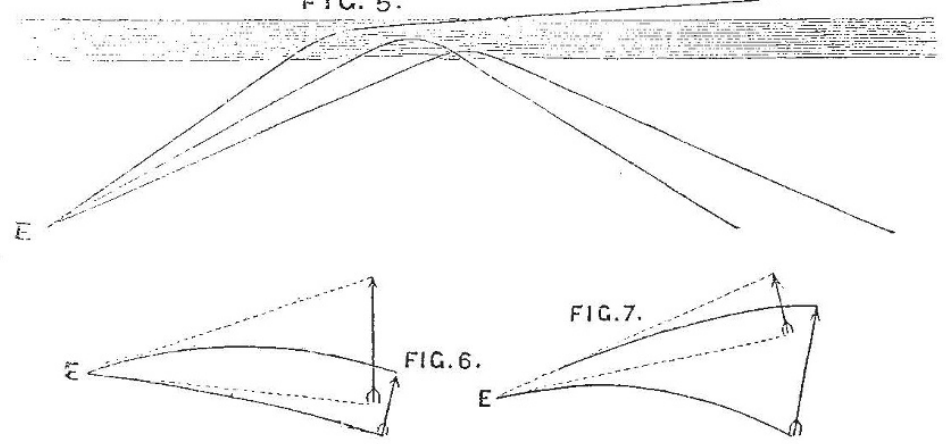

Plate I.

My esteemed colleague, Dr. James Thomson, has yreatly contributed to the clearness of our knowledge, as regards the d sturbing effect of the atmosphere upon the direction of a ray of light. He has recently published an investigation,* which, to say the least, is simpler and more satisfactory than any before given, of the precise law which determines the curved patt of a ray through the air.

Referring you for the details to the last chapter but one of my own recently published edition of Deschanel's

"Natural Philosophy," I will merely say that when a ray is rassing through a portion of air which is not equally * British Association Report, 1872, p. 4 r. dense all round it, it is deflected towards the side on which the density is greatest; and that the sharpness of the curvature, as measured by the change of direction for a given length of the ray, is directly proportional to the rate at which the density varies along the normal. Strictly speaking, I ought, instead of "density," to have said "absolute index of refraction, diminished by unity ;" but experiment has shown that the difference between these two statements, when there is no substance in question except air and aqueous vapour, is quite insignificant.

Supposing the stratification of the air to be strictly horizontal, it follows that a ray travelling vertically will not be bent at all, since there is no variation of density in the direction of its normal; and of all rays which traverse the same point, those which are horizontal will be bent the most, because the whole change of density is normal to them, and has a direct tendency to bend them downwards. For rays which are nearly horizontal, the curvature will be very nearly the same; and, as it is by such rays that we see the images which constitute mirage, the maximum bending of atmospheric rays is available for the explanation of the phenomena. In the average state of the atmosphere, the curvature of rays which are horizontal, or nearly so, is about one-fifth or one-sixth of the curvature of the earth's surface ; though it is to be remarked, by way of caution, that the connection between these two curvatures is merely accidental ; the curvature of the earth is not the cause, nor even a partial cause, of the curvature of rays.

Other things being equal, the curvature of rays should be greater in cold than in warm air, and greater with high than with low barometer; but these are not the principal modifying elements. The circumstance which it is most important to know, at any time, in order to predict the degree of curvature, is the rate at which the temperature changes with the height. The average change is a fall of about $\frac{7}{300}$ of a degree Fahr. per foot of ascent. A fall of one fifty-third of a degree per foot of ascent would make the air equally dense at all heights, and would cause rays to travel in absolutely straight lines. A more rapid fall than this would render the air aloft denser than that below, and would cause rays to bend up instead of down. The existence of denser, and therefore heavier air aloft, is obviously incompatible with stability of equilibrium ; but unstable equilibrium may endure for a time, even under statical conditions; and when there is a powerful cause at work, tending to raise the temperature of the lower strata, it is quite conceivable that the lower air may be heated faster than it can get away (if I may be allowed a somewhat loose expression); so that, although there is a perpetual diffusion going on, the heated air ascending, and cooler air from above taking its place, there is, nevertheless, a difference of temperature perpetually maintained, exceeding one-fiftieth of a degree per foot. The circumstances under which the Egyptian form of mirage is observed are precisely such as are fitted to produce this state of things. A fierce sun scorching the parched 
ground, while the air is excessively transparent to his rays ground, whes of surface, eminently conducive to the maintenance of unstable equilibrium-and absence of windsuch are the conditions under which this form of mirage appears. On the other hand, if the decrease of temperature upwards is slower than usual, the ordinary downward bending of rays will be increased, and if any physical cause, such as warm winds commencing aloft, before they cause, such as warth's surface, produces a reversal of the ordinary distribution of temperature, so that there is an increase upwards, instead of a decrease, this change will favour the downward bending of rays, which will, accordingly, be exaggerated; for the lower air, being not only under greater pressure, but being also colder than the upper air, will for a double reason be denser.

Capt. Scoresby states that "the curious refractions of the atmosphere in the polar regions are most frequent on the commencement or approach of easterly winds," and he elsewhere states that easterly and southerly winds are mild.

An increase of temperature upwards, at the rate of about one-sixteenth of a degree Fahr. per foot, would make the curvature of rays equal to that of the earth, so that a ray might encircle the globe. Any increase in the downward bending of rays increases the range of vision, by enabling them to bend round the horizon, which previously limited the view. The visible effect is precisely the same as if the convexity of the surface of the earth were diminished. And not only will objects which were previously beyond the horizon be brought into view, but objects which were previously visible near the horizon will become plainer, inasmuch as the rays by which they are seen will not pass so close to the intervening surface as before, but will traverse a higher portion of the air, which is less liable to be ob:cured by impurities.

Having now laid down the first principles, to which all effects of atmospheric refraction must be traced, we will proceed to some more particular applications.

I have recently been considering the question-what must be the law of density (or, more strictly, of refractive index) in a borizontally stratified atmosphere, in order that images formed by mirage may be perfectly sharp? and some of the diagrams placed before you will serve to explain the results which I have obtained.

First:-Neglect the curvature of the earth, and suppose the surface of uniform index to be plane; then the law required is as follows:--There must be a place of maximum index, at which the rate of variation of index with height must be zero; and as we ascend or descend from this plane of reference the rate of variation of index must continually increase in direct proportion to the distance. The rate must also be the same at equal distances above and below this plane of reference. The curvature of a horizontal, or nearly horizontal ray, will thus be simply proportional to distance from the plane of reference, and the bending from either side will be towards this plane. Rays may accordingly pierce this plane (which is indicated by a dotted line in Figs. $I$ and 2 ) again and again, any number of times, and every time that they do so they will undergo a reversal of curvature. The curvature at the point of crossing will be nil. The curves described will be what are called "harmonic curves," or "curves of sines," such as are represented in Figs. I and 2 ; subject to the restriction that we have only to do with rays which are so nearly horizontal that the cosines of their inclinations may be treated as unity. The distance between consecutive intersections will be the same for all
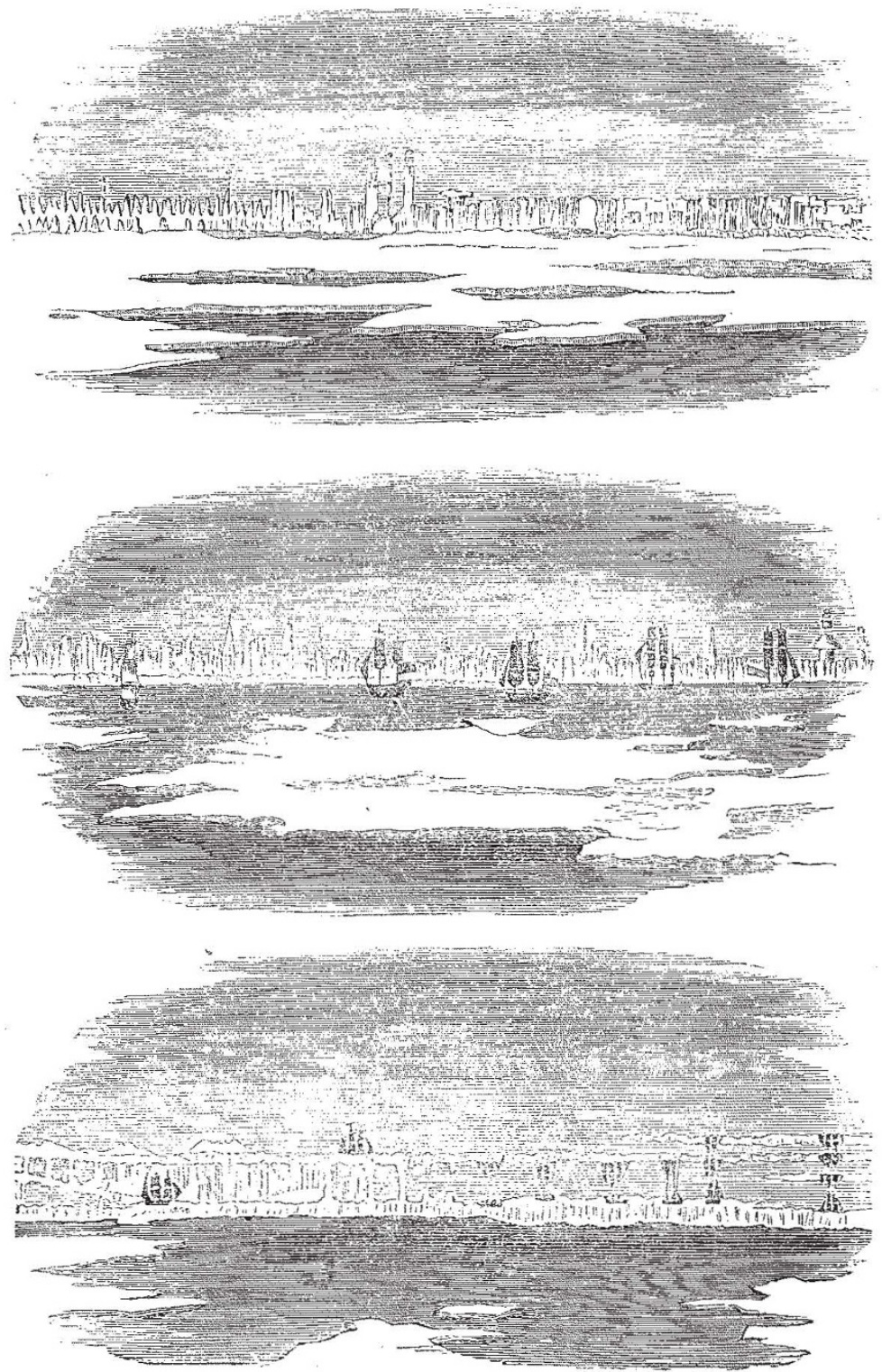

P.LATE II.

the curves, and is easily computed in terms of the constant which enters into the expression for the variation of index. A pencil of rays diverging in the same vertical plane from a point in the plane of reference, will thus converge accurately to another point in the plane, as represented in Fig I. Such a pair of points may be called principal conjugate foci. But this property of accurate convergence is not confined to pencils proceeding from points in the plane of reference. The same property attaches to pencils diverging from any point whatever; the conjugate focus 
being always a point at the same distance on the other side of the plane of reference, and the horizontal distance between the two being the same as in the preceding case. This property is illustrated by Fig. 2 .

It is obvious that the conjugate foci will occur not in pairs merely, but in sets of unlimited number; that is to say, raised proceeding originally from any one point will converge in succession to an indefinite number of other points, which will be alternately on opposide sides of the plane of reference. As every point on the surface of an object will thus have its conjugates, we shall have a succession of images of the object. The first image will be upside down, the second erect, and so on alternately. They will be what are technically called "real" images, and will be precisely equal and similar (except as regards inversion) to the object itself. It is of course to be understood that the action here described is confined to one dimension only, resembling that of a cylindrical rather than of a spherical lens. Rays are bent to and from the plane of reference, but in no other direction. This theoretically simple case is so important for the light which it throws upon the possibilities of atmospheric refraction, that we shall examine some of its consequences a llitle further.

What will be the appearance presented to the eye of an observer in any given position?

The case differs greatly from that of the images in ordinary optics, where the refracting instruments are glass lenses, and the eye sees the image by means of rays which travel in straight lines.

In the case now before us, the observer will in general see a virtual image, differing considerably, both in size and direction, not only from the object itself, but also from any one of the real images. The apparent direction of any point of the visible image is of course determined by drawing a tangent to the ray which enters the eye* (Figs. 6 and 7); and the visual angle, or, as we may call it, the apparent size of the object, will be the angle between two of these tangents. If the eye is a little distance (say a few feet) behind one of the real images, enormous magnification will be produced, for the image has the same linear height as the object, and is seen from a distance of a few feet, instead of from the real distance of the object; which we may suppose to be a few miles. We shall thus have enormous magnification of the vertical diameter of the object, while the horizontal diameter will of course be only of the natural size, since the rays have undergone no bending except up and down. An object whose breadth is equal to its height will thus be magnified into a tall column. Some appearances of this kind, copied from Scoresby's "Greenland," are represented in the first two figures of Plate II. The following is Scoresby's description ("Creenland," p. g6) :-

"Hummocks of ice assumed the forms of castles, obelisks, and spires, and the land presented extraordinary features. In some places the distant ice was so extrernely irregular, and appeared so full of pinnacles, that it resembled a forest of naked trees; in others it had the character of an extensive city crowded with churches, castles, and public edifices."

Again, on page $16_{3}$ of the same work :-

"At one period the phenomenon was so universal that the space in which the ship navigated seemed to be one vast circular area, bounded by a mural precipice of great elevation, of basaltic ice."

The magnificent columns which constitute a portion of the wonders of the Fata Morgana, at the Straits of Messina, are in like manner to be attributed to vertical magnification. And an appearance of the same kind, known as "the merry dancers," is often seen by boatmen off the Giant's Causeway, in looking over the Skerries towards Portrush.

* The letter $\mathbf{E}$, in all the figures, denotes the position of the obscrver's
If we could have density distributed symmetrically round an axis, instead of on the two sides of a plane, we might of course have magnification without distortion. Rut we can scarcely conceive of any arrangement at all resembling this existing in the atmosphere.

It is further to be remarked, that the apparent distance of one of our columnar images from the observer's eye is an ambiguous quantity. If judged by left and right displacement, it is the real distance of the object. If judged by up and down displacement, it is much less, being approximately the distance of the real image.

(To be continued.)

\section{SOME REMARKS ON DALTON'A FIRST TABLE OF ATOMIC WEIGHTS*}

$A S$ the Society is aware, the first table, containing the A relative weights of the ultimate particles of gaseous and other bodies, was published as the eighth and last paragraph to a paper by Dalton on the absorption of gases by water and other liquids, read before this Society on Oct. $2 \mathrm{I}, 1803$, but not printed until the year 1805 . There appears reason to believe that these numbers were obtained by Dalton after the date at which the paper was read, and that the paragraph in question was inserted at the time the paper was printed. The remarkable words with which he introduces this great principle give us but little clue to the methods which he employed for the determination of these first chemical constants, whilst in no subsequent publication, as in none of the papers which have come to light since his death, do we find any detailed explanation of how these actual numbers were arrived at. He says, $f$ "I am nearly persuaded that the circumstance" (viz., that of the different solubilities of gases in water) "depends upon the weight and number of the ultimate particles of the several gases: those whose particles are lightest and single being less absorbable, and the others more, according as they increase in weight and complexity. An inquiry into the relative weights of the ultimate particles of bodies is a subject, as far as I know, entirely new. I have been lately prosecuting this inquiry with remarkable success. The principle cannot be entered upon in this paper ; but I shall just subjoin the results, as far as they appear to be ascertained by my experiments."

Here follows the table of the relative weights of the atoms.

Table of the Relative Weights of the Ulimate Particles of Gaseous and other Bodies.

$\begin{array}{lcccccc}\text { Hydrogen } & \ldots & \ldots & \ldots & \ldots & \ldots & \text { I } \\ \text { Azot } \ldots & \ldots & \ldots & \ldots & \ldots & \ldots & 4 \cdot 2 \\ \text { Carbon } & \ldots & \ldots & \ldots & \ldots & \ldots & 4 \cdot 3 \\ \text { Ammonia } & \ldots & \ldots & \ldots & \ldots & \ldots & 5 \cdot 2 \\ \text { Oxygen } & \ldots & \ldots & \ldots & \ldots & \ldots & 5 \cdot 5 \\ \text { Water ... } & \ldots & \ldots & \ldots & \ldots & \ldots & 6 \cdot 5 \\ \text { Phosphorus } & \ldots & \ldots & \ldots & \ldots & \ldots & 7 \cdot 2 \\ \text { Phosphuretted hydrogen } & \ldots & \ldots & \ldots & 8 \cdot 2 \\ \text { Nitrous gas } \ldots & \ldots & \ldots & \ldots & \ldots & 9 \cdot 3 \\ \text { Ether .. } & \ldots & \ldots & \ldots & \ldots & \ldots & 9 \cdot 6 \\ \text { Gaseous oxide of carbon } & \ldots & \ldots & \ldots & 9 \cdot 8 \\ \text { Nitrous oxide... } & \ldots & \ldots & \ldots & \ldots & 13 \cdot 7 \\ \text { Sulphur } & \ldots & \ldots & \ldots & \ldots & \ldots & 14 \cdot 4 \\ \text { Nitric acid } \ldots & \ldots & \ldots & \ldots & \ldots & 15 \cdot 2 \\ \text { Sulphuretted hydrogen } & \ldots & \ldots & \ldots & 15 \cdot 4 \\ \text { Carbonic acid... } & \ldots & \ldots & \ldots & \ldots & 15 \cdot 3 \\ \text { Alcohol } & \ldots & \ldots & \ldots & \ldots & \ldots & 15 \cdot 1 \\ \text { Sulphurous acid } & \ldots & \ldots & \ldots & \ldots & 19 \cdot 9 \\ \text { Sulphuric acid } & \ldots & \ldots & \ldots & \ldots & 25 \cdot 4 \\ \text { Carburetted hydrogen from stagnant water... } & 6 \cdot 3 \\ \text { Olefiant gas } & \ldots & \ldots & \ldots & \ldots & \ldots & 5 \cdot 3\end{array}$

In the second part of his "New System of Chemical Philosophy," published in 1810, Dalton points out, under the description of each substance, the experimental evi* By Prof. H. F. Roscoe, F.R.S. ; read before the Literary and Philosophical Society of Manchester, Nov. 17,1874

t Manch. Mem., vol. i., Second Series, p. 286 